\title{
Inheritance of $\mathrm{dlm}$ and $\mathrm{ti}$ genes in Soybean
}

\author{
Mi Kyung Sung ${ }^{1}$, Min Hwan Kim${ }^{1}$, Hyung Jin Seo ${ }^{1}$, and Jong II Chung ${ }^{1}$ * \\ ${ }^{1}$ Department of Agronomy, Research Institute of Life Science, Gyeongsang National University, JinJu, Korea, 660-701
}

\begin{abstract}
$d l m$ mutant newly identified displays necrotic spots with chlorotic halo despite the absence of any detectable pathogens in soybean. Kunitz trypsin inhibitor (KTI) protein of mature soybean seed is a main anti-nutritional factor and is controlled by $T i$ allele in soybean seed. The objective of this research was to determine the linkage or independent assortment between $d l m$ allele and $t i$ allele. $\mathrm{F}_{2}$ population was made by crossing between "Gaechuck2ho" (DlmDlmtiti) and T363 (dlmdlmTiTi) parents. The normal leaf or disease lesion mimic leaf trait of parents and $\mathrm{F}_{2}$ individual plants was recorded at $\mathrm{R} 2$ and $\mathrm{R} 3$ growth stage from field. The random seeds from individual $\mathrm{F}_{2}$ plants harvested were analysed electrophoretically to determine the presence of the KTI protein. The disease lesion mimic trait was matched to $3: 1$ ratio at the 0.01 levels of probability. The absence of the KTI protein was controlled by a single recessive gene. In $\mathrm{F}_{2}$ generation, the ratios of $102 \mathrm{Ti} \mathrm{Dlm}_{-}: 21 \mathrm{Ti}$ dlmdlm $: 24 \mathrm{titiDlm} \_$: 4 titidlmdlm were observed. Segregation ratio gave a good fit to the $9: 3: 3: 1$ ratio based on $F_{2}$ generation at the 0.01 levels of probability. The data confirmed that $d l m$ allele controlling disease lesion mimic trait was inherited independently with the $t i$ allele controlling absence of KTI protein in soybean.
\end{abstract}

Keywords $d l m, t i$, Independent assortment, Linkage, Kunitz trypsin inhibitor, Soybean

\section{INTRODUCTION}

A new phenotypic traits are useful in genetic and breeding studies. By gamma-irradiated treatment, disease lesion mimic mutant have been identified in soybean [Glycine max (L.) Merr.,] leaf. Mutant displays necrotic spots with chlorotic halo despite the absence of any detectable pathogens. The mutant was behaved as a single recessive allele, designated $d l m$ (Chung et al. 1998). The $\mathrm{dlm}$ allele controlling disease lesion mimic trait is useful in basic research aimed at better understanding disease hypersensitive response and programmed cell death in soybean. Kim et al. (2005) reported that $d l m$ mutant was light-dependent and observed that the mutant showed a defect in starch degradation of chloroplasts during diurnal fluctuations. The position of $\mathrm{dlm}$ allele on linkage group were not reported. However, inheritance between $d l m$ trait and a few morphological traits was identified. The $d l m$ allele was inherited independently with the $P 1$ allele (controlling glabrous trait), the $y 9$ allele (controlling chlorophyll- deficient leaf trait), the $f$ allele (controlling fasciation stem trait) and the lf 2 allele (controlling sevenleaflet trait) in soybean (Jeong et al. 2007).

Soybean protein has been widely used in the food industry due to excellent nutritional quality and health benefit. But, the several antinutritional factors present in raw mature soybean seeds. Different trypsin inhibitors have been reported to be present in soybeans (Birk 1961, Frattali and Steiner 1968, Kunitz 1945), but much of the soybean trypsin inhibitor activity is thought to be due to Kunitz trypsin inhibitor (Rackis et al. 1962). Kunitz trypsin inhibitor (KTI) protein of mature soybean seed is a main anti-nutritional factor in soybean seed. KTI protein is a small and non-glycosylated protein containing 181 amino acid residues with $21.5 \mathrm{kDa}$. KTI protein was first isolated and crystallized from soybean seeds by Kunitz (1945). The Kunitz trypsin inhibitor protein strongly inhibits trypsin, thus reducing food intake by diminishing digestion and absorption. In USDA germplasm collection, two soybean accessions (PI157440 and PI196168) have been identified

Received Mar 2, 2013; Revised Mar 3, 2013; Accepted Mar 13, 2013; Published March 31, 2013

*Corresponding author Jong Il Chung, jongil@gnu.ac.kr, Tel: +82-55-772-1872, Fax: +82-55-772-1879 
which lacks KTI protein (Orf and Hymowitz 1979). Five electrophoretic forms of KTI have been discovered. The genetic control of four forms, Tia, Tib, Tic, and Tid, has been reported as a codominant multiple allelic series at a single locus (Sing et al. 1969; Hymowitz and Hadley 1972; Orf and Hymowitz 1979). Orf and Hymowitz (1979) also found out that the fifth form does not exhibit a soybean trypsin inhibitor-A2 band and is inherited as a recessive allele designated as ti. The Ti locus has been located on linkage group 9 in the classical linkage map of soybean (Hildebrand et al. 1980; Kiang 1987), which was integrated in linkage group A2 (chromosome 8) of the USDA/Iowa State University soybean molecular linkage map (Cregan et al. 1999). The genetic removal of the KTI protein will improve the nutritional value of soybean. Oliveira et al. (2007) observed that total isoflavone contents in KTI free soybean seed were higher than those in the normal soybean seed. Relationship between leaf trait and seed compositional trait is useful in genetic and breeding research of soybean. The objective of this research was to determine the linkage or independent assortment between dlm allele and ti allele.

\section{MATERIALS AND METHODS}

\section{Genetic materials}

Two parents were used to develop $F_{2}$ populations. "Gaechuck2ho" parent has titi genotype (KTI protein absent in mature seed) and normal leaf trait (DlmDlm genotype). T363 parent has the $d l m$ allele that controls disease lesion mimic trait in leaves ( $\mathrm{dlm} d \mathrm{dlm}$ genotype) and has KTI protein in mature seed (TiTi genotype). The seeds of "Gaechuck2ho" and T363 parents were planted to cross in a greenhouse. The crosses of "Gaechuck2ho" (DlmDlmtiti) $\times$ T363 (dlmdlmTiTi) were made and $\mathrm{F}_{1}$ seeds were obtained. $F_{1}$ seeds obtained were planted in a greenhouse. $F_{1}$ hybridity was confirmed on morphological traits. $F_{2}$ seeds from $\mathrm{F}_{1}$ plant confirmed were harvested. The seeds of parent and $F_{2}$ were planted in the field in Jun 2011. The normal leaf or disease lesion mimic leaf trait of parents and $F_{2}$ individual plants was recorded at R2 and R3 growth stage from field.

\section{Determination of Kunitz trypsin inhibitor protein}

Crude protein from parent seed and random seed from each $F_{2}$ plant harvested was extracted to determine the presence ('+') or absence ('-') of KTI protein electrophoretically. Seed coats were removed and were ground. The samples were incubated for $30 \mathrm{~min}$ (at room temperature) in $1 \mathrm{ml}$ Tris- $\mathrm{HCl}, \mathrm{pH} 8.0$, containing $1.56 \% \mathrm{v} / \mathrm{v} \beta$ -mercaptoethanol. After centrifugation, $50 \mu \mathrm{l}$ of the supernatant was added to an equivalent amount of $5 \mathrm{X}$ sample buffer [10\% w/v sodium dodecyl sulfate (SDS), 5 $0 \% \mathrm{v} / \mathrm{v}$ glycerol, $1.96 \% \mathrm{v} / \mathrm{v} \beta$-mercaptoethanol, $1 \mathrm{M}$ Tris-HCl, pH 6.8]. The samples were boiled at 97 ? for 5 $\mathrm{min}$ and then centrifuged. Two microliters of the supernatant were loaded on a $12 \%$ acrylamide SDS polyacrylamide gel electrophoresis (SDS-PAGE) medium gels in Owl Separation Systems Inc (Model : P9DS, Portsmouth, NH USA). Electrophoresis was performed at $120 \mathrm{~V}$ for $7 \mathrm{hrs}$. Gels were stained overnight in an aqueous solution of $0.25 \mathrm{~g}$ coomassie blue R250, 10\% acetic acid, and 45\% methanol. The gels were then destained with destaining solution (5\% acetic acid, 14\% methanol) for several hours. A WideRange SDS-PAGE molecular mass standard (Sigma Marker ${ }^{\mathrm{TM}}$, Product Code: M4038, St. Louis MO USA) containing $21.5 \mathrm{kDa}$ (for KTI protein) was used to aid recognition of samples lacking KTI protein. Chi-square analysis was used to test the goodness-of-fit of observed ratios with expected ratios for independent assortment or linkage.

\section{RESULTS AND DISCUSSION}

Leaf trait of $F_{1}$ plant obtained from the cross of "Gaechuck2ho" and T363 parents was normal. A necrotic spot on the leaf of $F_{1}$ plant was not observed. A total of 157 $\mathrm{F}_{2}$ plants were grown in field. Disease lesion mimic trait was segregated in $F_{2}$ population (Fig. 1). $126 F_{2}$ plants showed the normal leaf and $25 \mathrm{~F}_{2}$ plants showed disease lesion mimic trait (Table 1).

Chi-square value of 5.74 was higher than critical point of 3.84 at the 0.05 levels of probability and the value was lower than 6.635 point of 0.01 levels of probability. The disease lesion mimic trait was matched to $3: 1$ ratio at the 0.01 levels of probability. Previous studies observed that 


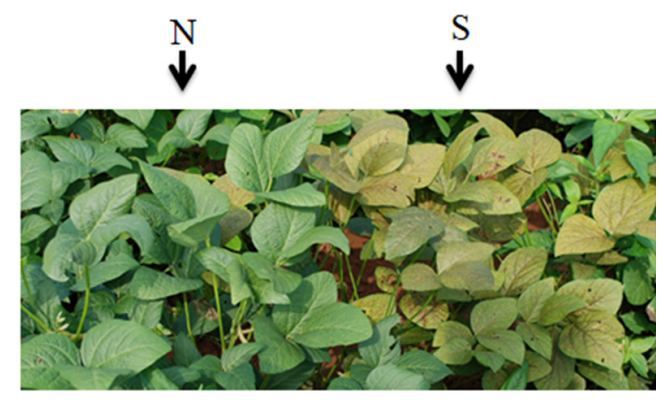

Fig. 1. Segregation of normal and disease lesion mimic trait in $F_{2}$ plant generation obtained from the cross of "Gaechuck2ho" (titiDlmDlm) and T363 (TiTidlmdlm). N: normal leaf type, S: necrotic spots with chlorotic halo leaf type.

disease lesion mimic trait in soybean leaf was inherited as a single recessive gene at the 0.05 levels of probability (Chung et al. 1998; Jeong et al. 2007). Deviation from the $3: 1$ ratio at the 0.05 levels of probability might be due to the small population size and death of a few plants with disease lesion mimic trait by bad field condition. All mature $F_{1}$ seeds obtained produced Kunitz trypsin inhibitor (KTI) protein, indicating that the presence of KTI protein was dominant to the absence of it. A part of the SDS-PAGE pattern for KTI protein that appeared in the parents and $\mathrm{F}_{2}$ plants is shown in Figure 2.

Bands for KTI protein were segregated in $\mathrm{F}_{2}$ generation. The segregation of $F_{2}$ generation for presence and absence

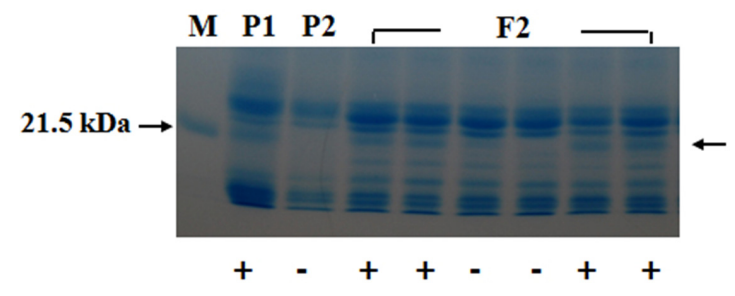

Fig. 2. Segregation of the Kunitz trypsin inhibitor (KTI) protein in the parents and $\mathrm{F}_{2}$ plants. P1:T363, P2: "Gaechuck2ho". +, -; presence and absence of KTI protein, respectively.

of KTI protein is summarized in Table 2.

Among $151 \mathrm{~F}_{2}$ plants harvested, $123 \mathrm{~F}_{2}$ plants showed KTI protein and $28 \mathrm{~F}_{2}$ plants did not show KTI protein. The segregation ration of the presence or absence of the KTI protein in the $F_{2}$ plants well fitted to an expected 3:1 ratio $(\chi$ $\left.{ }^{2}=3.35, P=0.066\right)$. This result shows that the absence of the KTI protein is controlled by a single recessive gene. Previous studies have shown that KTI protein is inherited as a single recessive allele (Orf and Hymowitz, 1979; Kim et al. 2006; Eun et al. 2012).

The Segregation between $d l m$ allele and $t i$ allele was observed (Table 3). The $F_{2}$ plant ratios of 102 normal leaf type, KTI protein present: 24 normal leaf type, KTI protein absent: 21 disease lesion mimic type, KTI protein present : 4 disease lesion mimic type, KTI protein absent were observed.

Table 1. Inheritance of $d l m$ allele in segregated $\mathrm{F}_{2}$ plant population obtained from the cross of "Gaechuck2ho" (titiDlmDlm) and T363 (TiTidlmdlm).

\begin{tabular}{|c|c|c|c|c|c|c|}
\hline \multirow{2}{*}{$\begin{array}{l}\text { No. of } \\
F_{2} \text { plant }\end{array}$} & & \multicolumn{2}{|c|}{ Leaf trait } & \multirow{2}{*}{$\begin{array}{l}\text { Expected } \\
\text { ratio }\end{array}$} & \multirow[b]{2}{*}{$\chi^{2}$} & \multirow[b]{2}{*}{$\mathrm{P}$} \\
\hline & & $\begin{array}{l}\text { Normal } \\
\left(D l m \_\right)\end{array}$ & $\begin{array}{l}\text { Necrotic } \\
(\mathrm{dlm} d \mathrm{~lm})\end{array}$ & & & \\
\hline & Observed & 126 & 25 & $3: 1$ & 5.74 & 0.016 \\
\hline & Expected & 113.25 & 37.75 & & & \\
\hline
\end{tabular}

Table 2. Segregation of the presence or absence of the Kunitz trypsin inhibitor (KTI) protein in $\mathrm{F}_{2}$ generation from the cross between "Gaechuck2ho" and T363.

\begin{tabular}{ccccc}
\hline \hline KTI & \multicolumn{2}{c}{ No. of $F_{2}$ plant } & & $\chi^{2}$ value \\
Protein & Observed & Expected & & P \\
\cline { 2 - 3 } & 123 & 113.25 & \multirow{2}{*}{3.35} & 0.066 \\
\hline+ & 28 & 37.75 & & \\
\hline
\end{tabular}

,$+-:$ presence(+) or absence(-) of KTI protein. 
Table 3. Segregation of $T i(t i)$ and $D l m(d l m)$ alleles in $\mathrm{F}_{2}$ generations obtained from the cross between "Gaechuck2ho" (DlmDlmtiti) and T363 (dlmdlmTiTi) parents.

\begin{tabular}{|c|c|c|c|c|c|}
\hline \multirow{2}{*}{ Genotype } & \multicolumn{2}{|c|}{$\mathrm{F}_{2}$ generation } & \multirow{2}{*}{$\begin{array}{l}\text { Expected } \\
\text { ratio }\end{array}$} & \multirow{2}{*}{$\chi^{2}$} & \multirow{2}{*}{$\mathrm{P}$} \\
\hline & Observed & Expected & & & \\
\hline$T i_{-} D l m_{-}$ & 102 & 84.94 & 9 & 9.106 & 0.027 \\
\hline Ti_dlmdlm & 21 & 28.31 & 3 & & \\
\hline titiDlm_ & 24 & 28.31 & 3 & & \\
\hline titi dlmdlm & 4 & 9.44 & 1 & & \\
\hline
\end{tabular}

Segregation ratio gave a good fit to the $9: 3: 3: 1$ ratio based on $\mathrm{F}_{2}$ generation at the 0.01 levels of probability (Chi-square value $=9.106, P=0.027$ ). Chi-square value of 9.106 was higher than critical point of 7.815 at the 0.05 levels of probability and the value was lower than 11.345 point of 0.01 levels of probability. Generally, the plant with both disease lesion mimic type and KTI protein absent type (titidlmdlm genotype) is very weak in growth. By the bad field condition, a few $\mathrm{F}_{2}$ plant with titidlmdlm genotype was died in early growth stage. By this reason, deviation from the $9: 3: 3: 1$ ratio at the 0.05 levels of probability was observed. However, at the 0.01 levels of probability, the data confirmed that $\mathrm{dlm}$ allele controlling disease lesion mimic trait was inherited independently with the $t i$ allele controlling absence of KTI protein in soybean. So far, the position of Dlm locus on classical linkage group or molecular linkage map has not been identified. The $\mathrm{dlm}$ allele was inherited independently with the $P 1$ allele, the $y 9$ allele, the $f$ allele and the lf 2 allele (Jeong et al. 2007). From these results, $\mathrm{dlm}$ allele would not be located on classical linkage group 9 (molecular linkage group A2, chromosome 8 ) in soybean. These results will be useful in genetic and breeding research of soybean.

\section{CONCLUSION}

To determine the genetic relationship between $\mathrm{dlm}$ allele controlling disease lesion mimic trait and $t i$ allele controlling the presence or absence of Kunitz trypsin inhibitor (KTI) protein in mature seed, $\mathrm{F}_{2}$ population was developed from the cross of "Gaechuck2ho (DlmDlmtiti) and T363 (dlmdlmTiTi) parents. The leaf trait of parents and $F_{2}$ individual plants was recorded at R2 and R3 growth stage from field and the random seeds from individual $F_{2}$ plants harvested was analysed to determine the presence of the KTI protein. A total of $157 \mathrm{~F}_{2}$ plants were grown in field. $126 \mathrm{~F}_{2}$ plants showed the normal leaf and $25 \mathrm{~F}_{2}$ plants showed disease lesion mimic trait. The disease lesion mimic trait was matched to $3: 1$ ratio at the 0.01 levels of probability. Among $151 \mathrm{~F}_{2}$ plants harvested, $123 \mathrm{~F}_{2}$ plants showed KTI protein and $28 \mathrm{~F}_{2}$ plants did not show KTI protein. The segregation ratio of the presence or absence of the KTI protein in the $\mathrm{F}_{2}$ generation was well fitted to an expected 3:1 ratio $\left(\chi^{2}=3.35, P=0.066\right)$. This result shows that the absence of the KTI protein is controlled by a single recessive gene. The ratios of $102 \mathrm{Ti} \_\mathrm{Dlm}$ : $21 \mathrm{Ti}$ _dlmdlm : 24 titiDlm_: 4 titidlmdlm were observed. Segregation ratio gave a good fit to the $9: 3: 3: 1$ ratio based on $\mathrm{F}_{2}$ generation at the 0.01 levels of probability (Chi-square value $=9.106$, $P=0.027)$. The data confirmed that $d l m$ allele controlling disease lesion mimic trait was inherited independently with the $t i$ allele controlling absence of KTI protein in soybean.

\section{ACKNOWLEDGEMENTS}

This research was supported by Basic Science Research Program through the National Research Foundation of Korea (NRF) funded by the Ministry of Education, Science and Technology (grant number: 2010-0002513)

\section{REFERENCES}

Birk Y. 1961. Purification and some properties of a highly activeof trypsin and chymotrypsin from soybeans. Biochem. Acta. 54:378-381. 
Chung J, Staswick PE, Graef GL, Wysong DS and Specht JE. 1998. Inheritance of a disease lesion limic mutant in soybean. J Hered. 89:363-365.

Cregan PB, Jarvik T, Bush AL, Shoemaker RC, Lark KG, Kahler AL, Kaya N, VanToai TT, Lohnes DG, Chung JI and Specht JE. 1999. An integrated genetic linkage map of the soybeanme. Crop Sci. 39:1464-1490.

Frattali V and Steiner RF. 1968. Soybean inhibitor. I. Separationssome properties of three inhibitors from commercial crudetrypsin inhibitors. Biochem. 7:521-530.

Hymowitz T and Hadley HH. 1972. Inheritance of a trypsinvariant in seed protein of soybeans. Crop Sci. 12:197-198.

Hildebrand DF, Orf JH and Hymowitz T. 1980. Inheritance of anacid phosphatase and its linkage with the Kunitz trypsin inhibitorseed protein of soybeans. Crop Sci. 20:83-85.

Jeong WH, Nam KC, Park MS, Lee KJ, Kim MS and Chung JI. 2007. Independent imheritance of $\mathrm{dlm}$ allele with lf2 and $P 1$ alleles in soybean (Glycine $\max$ L.). Korean J. Breed Sci. 39(2):232-235.

Jeong WH, Nam KC, Park MS, Lee KJ, Kim MS and Chung JI. 2007. Inheritance of $d \operatorname{lm}$ gene with $f$ and $y 9$ alleles in soybean (Glycine $\max$ L.). Korean J. Breed. Sci. 39(4):473-477.

Kunitz M. 1945. Crystallization of a soybean trypsin inhibitor from soybean. Science. 101:668-669.
Kiang YT. 1987. Mapping three protein loci on a soybean chromosome. Crop Sci. 27:44-46.

Kim HK, Kim YJ, Paek KH, Chung JI and Kim JK. 2005. The phenotype of the soybean disease-lesion mimic $(\mathrm{dlm})$ mutant is light-dependent and associated with chloroplast function. Plant Pathol. J. 21(4):395-401.

Kim MS, Park MJ, Jeong WH, Nam KC and Chung JI. 2006. SSRmarker tightly linked to the $T i$ locus in [soybean Glycine max (L.) Merr.]. Euphytica 152:361-366.

Oliveira MIP, Nilton D, Piovesan ICJ, Everaldo GB, Maurilio A and Moreira LO. 2007. Protein, oil, and isoflavone contents in lipoxygenase- and kunitz trypsin inhibitordeficient soybean seeds. Chromatographia. 66:521-527.

Orf JH and Hymowitz T. 1979. Inheritance of the absence of thetrypsin inhibitor in seed protein of soybeans. Crop Sci. 19:107-109.

Rackis JJ, Sasame HA, Mann RR, Anderson RL and Smith AK. 1962. Soybean trypsin inhibitors: Isolation, purification andproperties.Biochem. Biophys. 98:471-478.

Singh L, Wilson CM and Hadley HH. 1969. Geneticin soybean trypsin inhibitors separated by disc electrophoresis. Crop Sci. 9:489-491.

Eun HH, Sung MK, Baek WJ, Shim SI, Kim MC and Chung JI. 2012. Inheritance of Kunitz trypsin inhibitor and P34 protein in soybean seed. Korean J. Crop Sci. 57(1):78-82. 